\title{
Availability and use of mycotoxin binders in selected urban and Peri-urban areas of Kenya
}

\author{
Florence Mutua $^{1,2} \cdot$ Johanna Lindahl ${ }^{1,3,4} \cdot$ Delia Grace $^{1}$ \\ Received: 18 September 2018 / Accepted: 6 March 2019 / Published online: 27 March 2019 \\ (C) The Author(s) 2019
}

\begin{abstract}
Aflatoxins are carcinogenic, toxic and immunosuppressive substances produced by some species of the fungal genus, Aspergillus. Consumption of aflatoxins can have serious health effects. Widespread in the tropical and sub-tropical world, aflatoxin B1 (AFB1) is found in many staple foods and feeds; after ingestion it is metabolized to aflatoxin M1 (AFM1), which transfers to milk. One option for reducing aflatoxin concentration in cow milk is addition of mycotoxin binders to animal feeds, but little is known about this practice in the smallholder dairy systems in developing countries. We undertook a study to investigate the availability and use of mycotoxin binders in selected urban and peri-urban areas of Kenya. Data were collected using key informant interviews with government officials and one-to-one questionnaire-guided interviews with agrovet outlets (shops that sell animal health products (such as antibiotics) and crop inputs (such as fertilizers) and feed processors. Nine different mycotoxin binder types were reported. They were sold by $8 \%$ (4/49) of agrovets and 33\% (3/9) of feed processors. The binders were purchased by farmers formulating their own feeds and by feed processors. Our review of regulations found that incorporating binders into animal feeds is not mandatory and there are no specific standards governing their use in Kenya. Feed processors are expected to respect the maximum allowable limit of $5 \mu \mathrm{g} / \mathrm{kg}$ for AFB1 in complete feeds. Gaps in the local feed supplies that may potentially lead to increased risks of aflatoxin exposure through milk are discussed. This study provides key data on the availability and local use of mycotoxin binders, which were previously lacking. However, there is a need for continued research on their effectiveness in the local smallholder context, in order to promote their appropriate use.
\end{abstract}

Keywords Aflatoxins $\cdot$ Mycotoxin binders $\cdot$ Standards and regulations $\cdot$ Smallholder dairy value chains $\cdot$ Food safety $\cdot$ Feed safety

Florence Mutua

f.mutua@cgiar.org

Johanna Lindahl

j.lindahl@cgiar.org

Delia Grace

d.grace@ cgiar.org

1 International Livestock Research Institute, P. O. Box 30709, Nairobi 00100, Kenya

2 Department of Public Health, Pharmacology \& Toxicology, University of Nairobi, P.O. Box 29053 00625, Nairobi, Kenya

3 Department of Clinical Sciences, Swedish University of Agricultural Sciences, P. O. Box 70790, 75007 Uppsala, SE, Sweden

4 Zoonoses Science Centre, Uppsala University, P. O. Box 70790 se, 75007 Uppsala, Sweden

\section{Introduction}

Aflatoxins are mainly produced by the fungal species Aspergillus flavus and A. parasiticus. In Kenya, maize and groundnuts are frequently contaminated, as well as animal feed. Aflatoxin levels above the WHO/FAO limit of $5 \mu \mathrm{g} / \mathrm{kg}$ (for aflatoxin B1 (AFB1) in feeds) and $0.05 \mu \mathrm{g} / \mathrm{kg}$ (for aflatoxin M1 (AFM1) in milk) have often been reported in Kenya (Lewis et al. 2005; Mwihia et al. 2008; Kang'ethe and Lang'a 2009; Mutegi et al. 2012; Senerwa et al. 2016). Human exposure is well documented (Yard et al. 2013; Kang'ethe et al. 2017), and has resulted in serious and acute outbreaks of aflatoxicosis (Azziz-Baumgartner et al. 2005). Ingestion of AFB1 can have significant health effects in both animals and humans. It is toxic to the liver and, when bound to cellular DNA and RNA, causes genetic alterations with mutagenic, teratogenic, and carcinogenic effects (McLean and Dutton 1995; Wild and Turner 2002). The International Agency for 
Research on Cancer (IARC) has classified all aflatoxins as type 1 carcinogens (IARC 2012).

Aflatoxin M1 (AFM1), a metabolite of AFB1, formed when AFB1 is ingested by people or animals, can be found in milk from cows fed on AFB1- contaminated feed. Carryover from feed to milk is influenced by a range of factors including milk production, breed, health and nutritional status. The best approach for reducing aflatoxin contamination in animal feeds is prevention of mycotoxin formation (Bulent and Dobson 2009). Several pre-harvest and post-harvest aflatoxin reduction technologies are recommended for this. However, even if used, the risk of feed contamination remains high, especially in a country such as Kenya where the food supply systems are complex, regulatory enforcement is weak, the fungi producing aflatoxins are ubiquitous and food considered unfit for humans is often given to animals (Kiama et al. 2016). In this context, the use of adsorbing agents or mycotoxin binders is promising. Binders generally consist of clay or yeast-derived products. Several clay materials have been used including bentonite, zeolite and hydrated sodium calcium aluminosilicate (HSCAS). Binders work by sequestering the toxins in the gastro-intestinal tract of the animal with the resulting complex (binder*toxin) being eliminated through faeces. As a result, toxin uptake and bioavailability are reduced, the animal is protected from the negative health effects, and safer milk is produced.

Mycotoxin binders are popular because of their low cost, ease of use, and effectiveness in small quantities (Marroquin-Cardona et al. 2009; Murugesan et al. 2015). However, while many binders are marketed worldwide, their effectiveness in preventing aflatoxin uptake varies with the type and amount added. One review cited reductions of AFM1 in milk ranging between 4\% and 65\% (Giovati et al. 2015). Moreover, some binders may be ineffective: a study in Brazil showed that about $64 \%$ of the products on the market were not effective (Zaviezo 2009; Mallmann and Dilkin 2012).

The large number of different binders available and evidence of varying quality, efficacy and safety, makes it important to understand if, and how, binders are used in a given context. The objectives of this study were to 1) assess the current use of mycotoxin binders in Kenya (which types, who sells them, who purchases them, what doses are used), and 2) review standards regulating the use of the products in the country. The results are intended to support development of suitable standards for mycotoxin binder regulation, in addition to providing a basis for further research on their effectiveness in local smallholder systems. Our study focused on outlets retailing animal feed. For the purposes of our study, we define "agrovet" as shops that sell animal health products (such as antibiotics), crop inputs (such as fertilizers) and animal feeds. The last includes complete feeds, or raw materials (e.g. maize bran, cotton seed cake), or both.
Ethical approval for this work was obtained from ILRI's Institutional Research Ethics Committee (IREC) approval number: ILRIIREC2017-10/2. Signed informed consent was sought for all the study participants: agrovet dealers, feed processors, and government officials.

\section{Methods}

\subsection{Study area}

This study was conducted in selected urban and peri-urban areas of the Nairobi (Kasarani sub-county) and Kisumu counties, where smallholder dairy farming is common and aflatoxins are encountered in the milk sold (Anyango et al. 2018; Kagera et al. 2019) (Fig. 1). Kasarani has five administrative areas, namely, Clay City, Mwiki, Kasarani, Njiru and Ruai, which were all included in the study. In Kisumu, we focused on five sub-counties, namely Kisumu East, Nyando, Kisumu West, Kisumu Central and Muhoroni sub-counties. The areas were purposively selected because of their high levels of urban and peri-urban smallholder dairy production. Data were collected in the period from April to May 2018.

\subsection{Study population}

The study population included agrovets (outlets that sell veterinary and agricultural products) and animal feed sellers (feed outlets and millers). We included established cereal millers who were primarily engaged in feed processing.

\subsection{Sampling and sample size estimation}

Using the formula from Dohoo et al. (2003), with a proportion of shops that stock or sell binders estimated at $30 \%$ and a precision estimate of $10 \%$, our calculated sample size (n) was 80 outlets. Based on the list obtained from government offices in both areas, there were approximately 108 eligible outlets, which included agrovets, feed shops, and millers in the study area. Of these, 80 were randomly sampled. However, 22 (28\%) were excluded because they were operated by an owner already sampled (so stock and management characteristics were likely to be similar), or only dealt with crop inputs, or the attendants did not have time for interview at the time of the visit. Both the public health section of the Directorate of Veterinary services (DVS) and Kenya Bureau of Standards (KEBS) were included in the study, owing to their role in animal feed regulations, and their specific interest in mycotoxin binder usage in the country. An interview meeting was arranged after having contacted the stakeholders by email and shared details of research work including an interview guide that was used in the study. 


\section{Data collection}

\subsection{Questionnaire interviews with agrovet shop owners and feed millers}

Data from agrovet and feed milling outlets were collected using questionnaires administered through face-to- face interviews. Briefly, the questionnaire covered the binder types available in the Kenyan markets, who sells them, their uses, available quantities, and retail prices. Where it was practically possible, we requested to be shown the mycotoxin binder types available at the time of the visit. Subsequently, for reported type, we performed a website search to extract more data on the product (e.g. mixing rates, composition, quantities packed). While administering the questionnaire to feed millers, we probed for data on raw material supply chain and their perceived sources of aflatoxin contamination.

\subsection{Key informant interviews}

These interviews were conducted with government officials in charge of animal feed standards and regulation of mycotoxin binder usage in the country. A checklist was developed to guide the discussions, which included questions on the effectiveness of available mycotoxin binders, the process of importing these, regulations governing their use, and suggestions on what could possibly be done to improve their use in the country. A more in-depth description of Novasil@ is provided, for two reasons, 1) its efficacy in binding aflatoxins has been demonstrated in a number of studies and 2) to inform another study on potential feasibility for use in smallholder

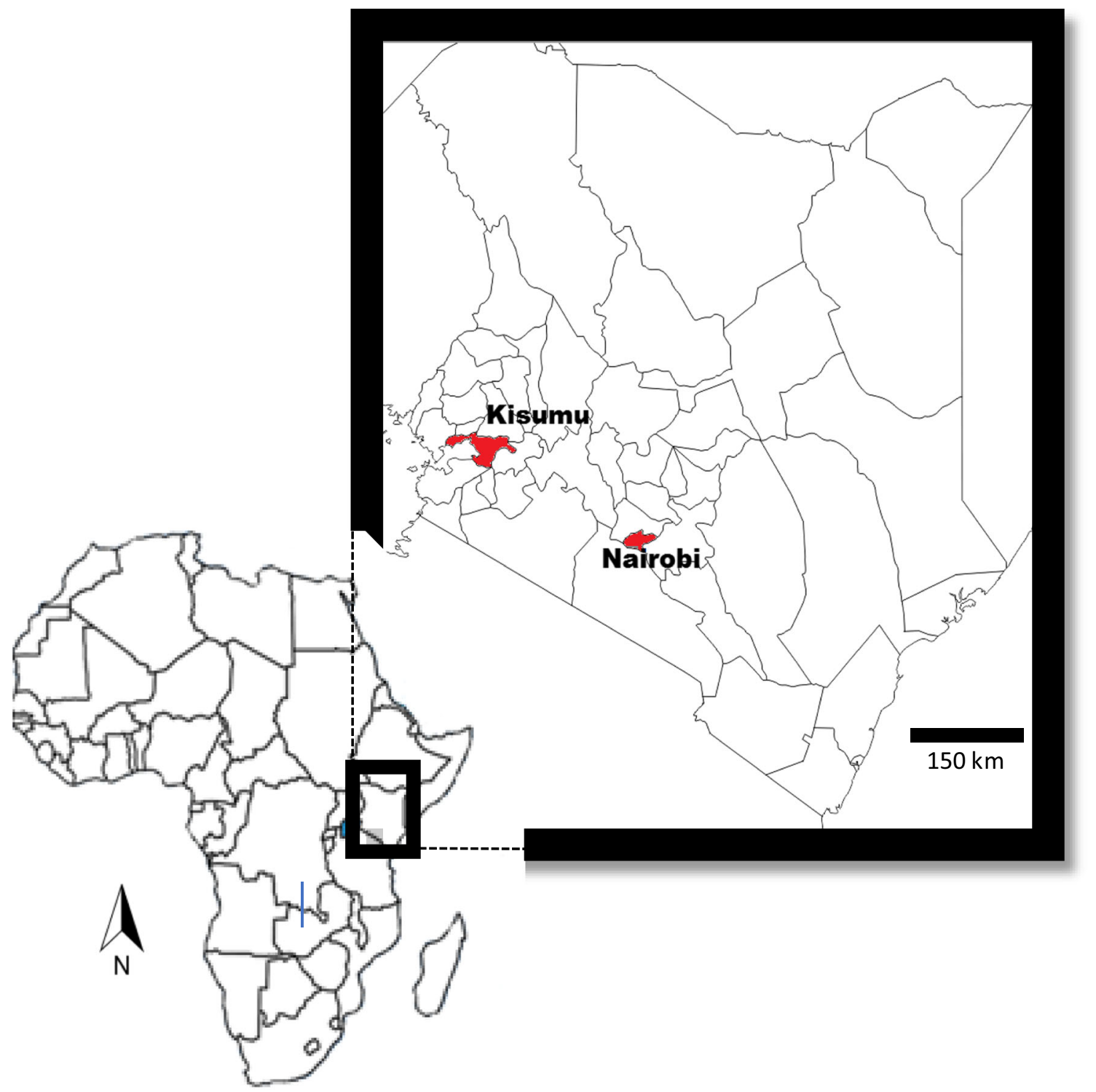

Fig. 1 Map showing the location of Counties (Kisumu and Nairobi) considered in the mycotoxin binder survey, April-May 2018 
dairy systems (with 1-2 cows) which constitute a large proportion of the farmers in the study areas (Kagera et al. 2019).

\subsection{Data entry and analyses}

An MS Excel® (2007) database was designed and the survey data were entered and cleaned. We used Stata ${ }^{\circledR}$ (Stata 2017) to descriptively analyse the data, with results being presented as frequency tables and graphs. For data on binder prices, an average estimate was calculated in cases where two or more price tags (per kg) were given for the same binder type. For other data (i.e. key informant interviews, probed data from feed millers), a description for each sub-section was compiled (e.g. process of importing binders, why aflatoxin contamination has remained a problem, and sources of contamination).

\section{Results}

\subsection{Characteristics of sampled agrovet shops}

Most of the surveyed outlets ( $84 \%$; 49 out of 58) were agrovet shops i.e. those that sold a combination of animal health, crop or animal feed products. The outlets sold feeds $(75 \%)$, veterinary products (73\%) and crop inputs (79\%) (Fig. 2). Thirty percent $(n=36)$ of the veterinary outlets did not sell injectable medicines as the Kenya Veterinary Board (KVB) does not permit them to handle these products. Two of the agrovet outlets also produced animal feeds, although on a small scale. Outlets that stocked animal feeds sold either complete feeds or raw materials (e.g. maize germ, sunflower seeds, wheat bran, "omena" fish (the silver cyprinid, Rastrineobola argentea), broken rice, cotton cake etc.). Some farmers used motorcycle operators to purchase and deliver feeds to their farms. For marketing purposes, outlets selling feeds displayed them in open spaces just outside their shops. Other businesses that were also operated through the agrovet shops included mobile money services popularly known as "mpesa", sale of cooking gases, hay, as well as eggs.

\subsection{Characteristics of feed millers}

Out of the 11 feed millers incorporated in the study, two were also agrovets and were therefore covered in the agrovet section, while the rest (9) were only engaged in animal feed processing. Millers distributed their feeds either through their own distribution outlets or as direct sales to farmers, and agrovets, who would in turn sell to the farmers. Their sources of raw materials included Tanzania (sunflower, cotton seed cake, polished rice), Uganda (rice germ and maize germ) and Rwanda (mostly sunflower). The reasons why millers preferred to import included 1) the non- or limited availability of the products in Kenya, 2) cheaper prices by up to 3 Kenya shillings (Ksh, USD 0.03) per kilogram of raw material and 3) perception that these were of better quality compared to what is locally available. Feed millers complained of poor quality of imported maize bran, which they said had high moisture content and often spoiled quickly. As a routine, and in order to allow for complete peeling of grains, maize millers in source countries add water to the maize during processing. The aim is to produce flour that is of premium quality but with less consideration on the quality of the by-products, such as the resulting bran. Raw materials meant for feed production can also become spoilt as a result of rains during transportation.

\subsection{Use of mycotoxin binding products}

All feed processors knew about mycotoxin binders but only about a half (52\%) of agrovet sellers had heard of them. The binders were sold by $8 \%(4 / 49)$ of the agrovets and 33\% (3/9) of the feed processors. Figure 3 summarises the main reasons why the surveyed agrovets did not sell mycotoxin binders. This chart is based on 17 agrovet shops who were not selling mycotoxin binders and whose respondents had heard of the product.
Fig. 2 Products and services offered by agrovet shops operating in the selected urban and peri-urban areas of Nairobi and Kisumu, April-May 2018

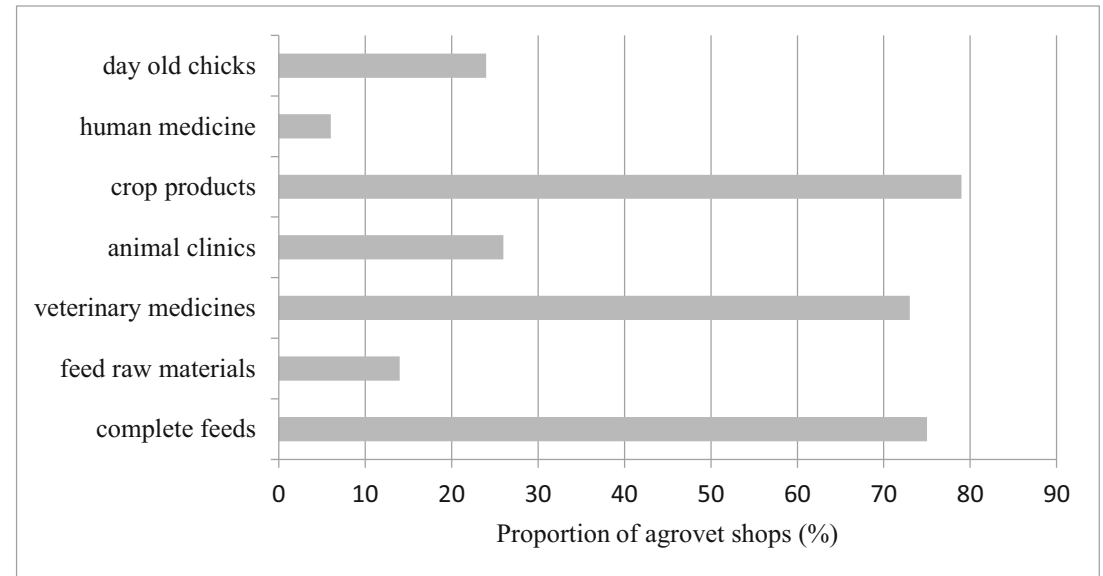


Binders were purchased either by farmers formulating their own feeds, or by feed processors (two feed processors sold binders to fellow feed processors). Based on records from the Public Health department of the DVS, between January and March 2018, approximately $60 \mathrm{t}$ of mycotoxin binders were imported, an amount about three times what was imported in a similar period in 2017. Novasil ${ }^{\circledR}$ and Mycosorb ${ }^{\circledR}$ were said to be the most popular mycotoxin binders. Other products also locally marketed as mycotoxin binders included Hepatox®, Bedgen 40 liquid $₫$ and Livergenplus $®$ which were given to animals (usually chickens) known to have been fed on mouldy feeds or those clinically presenting with aflatoxicosis. These oral formulations are indicated for the treatment of several animal health problems including aflatoxicosis and enteric infections.

Three processors sometimes added mycotoxin binders to their feeds, and when probed for reasons for this selective usage, one said "...we only use binders when we have wheat with high moisture content, and also for maize germ from Uganda", and another "we add the binder for ingredients that come through the port, e.g. rice/dog biscuits, as these get wet at the port especially portions that are kept next to the container during transport". The third processor added mycotoxin binder only for pig, chick and broiler feeds as these are thought to be more sensitive to aflatoxins. The rest of the processors included binders in all their processed feeds. A summary of the binder types observed during the study period, with indications for their use, dosages and quantities sold is given in Table 1. The product T5Z® was also reported but has not been included in the summary as data about the product was limited.

Data on binder amounts purchased by farmers was available in 5 outlets, 4 of which indicated that farmers purchased quantities of $1 \mathrm{~kg}$ and at costs ranging from between Ksh 290 to $1100 / \mathrm{kg}$ (Table 2). In one of the agrovet outlets, the attendant had a machine that could measure small quantities of the binder for farmers, some of whom requested to be helped mix rations based on their own specifications.

\subsection{Aflatoxin contamination problems}

As a follow-up to the question on the use of mycotoxin binders by feed processors, we probed the reasons why aflatoxins continue to be detected in milk produced in urban and peri-urban areas, in spite of the reported use of mycotoxin binders by feed millers. Table 3 is a summary of the various responses obtained.

\subsection{Standards and regulations on the use of mycotoxin binders}

The office of the Directorate of Veterinary services (DVS) regulates the use of mycotoxin binders in the country. The Kenya Bureau of Standards (KEBS) is mandated to establish and enforce national standards (www.kebs.org). The Animal Feed Technical Committee is in charge of developing standards for animal feeds and KEBS is the secretariat. The committee is composed of representatives from the Ministry of Agriculture, the DVS, feed manufacturers, the Government Chemist, universities and consumer information network. Briefly, the process requires developing an initial draft, which may be reviewed several times before being submitted for approval by the Standards Approval Committee. The approved document is gazetted for use in quality and surveillance assessments. There are no specific standards that govern the use of mycotoxin binders in Kenya. Mycotoxin binders are imported as additives and their inclusion in feeds is not mandatory. Only the complete feed is required to comply with set standards for aflatoxin contamination. Cases where feed processors request to be exempted from compliance have been reported. For example, samples may test positive with levels exceeding the permitted level but the feed processor requests exemption on the basis of having reduced the risk of contamination using mycotoxin binders. Such requests are always declined.
Fig. 3 Summary of reasons why a total of 17 agrovet outlets in Kisumu and Kasarani, Kenya, were not stocking mycotoxin binders, April-May 2018

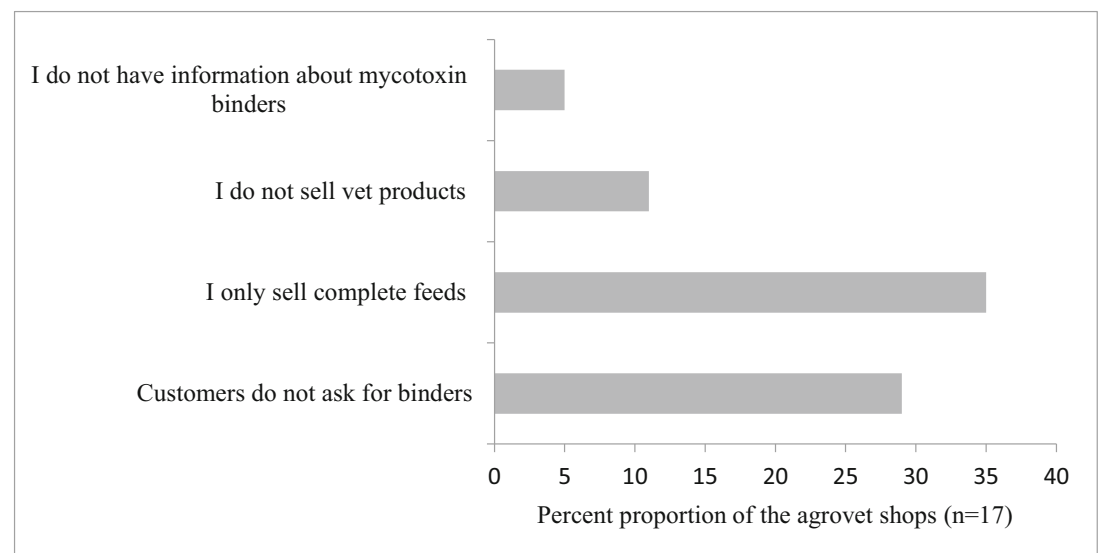




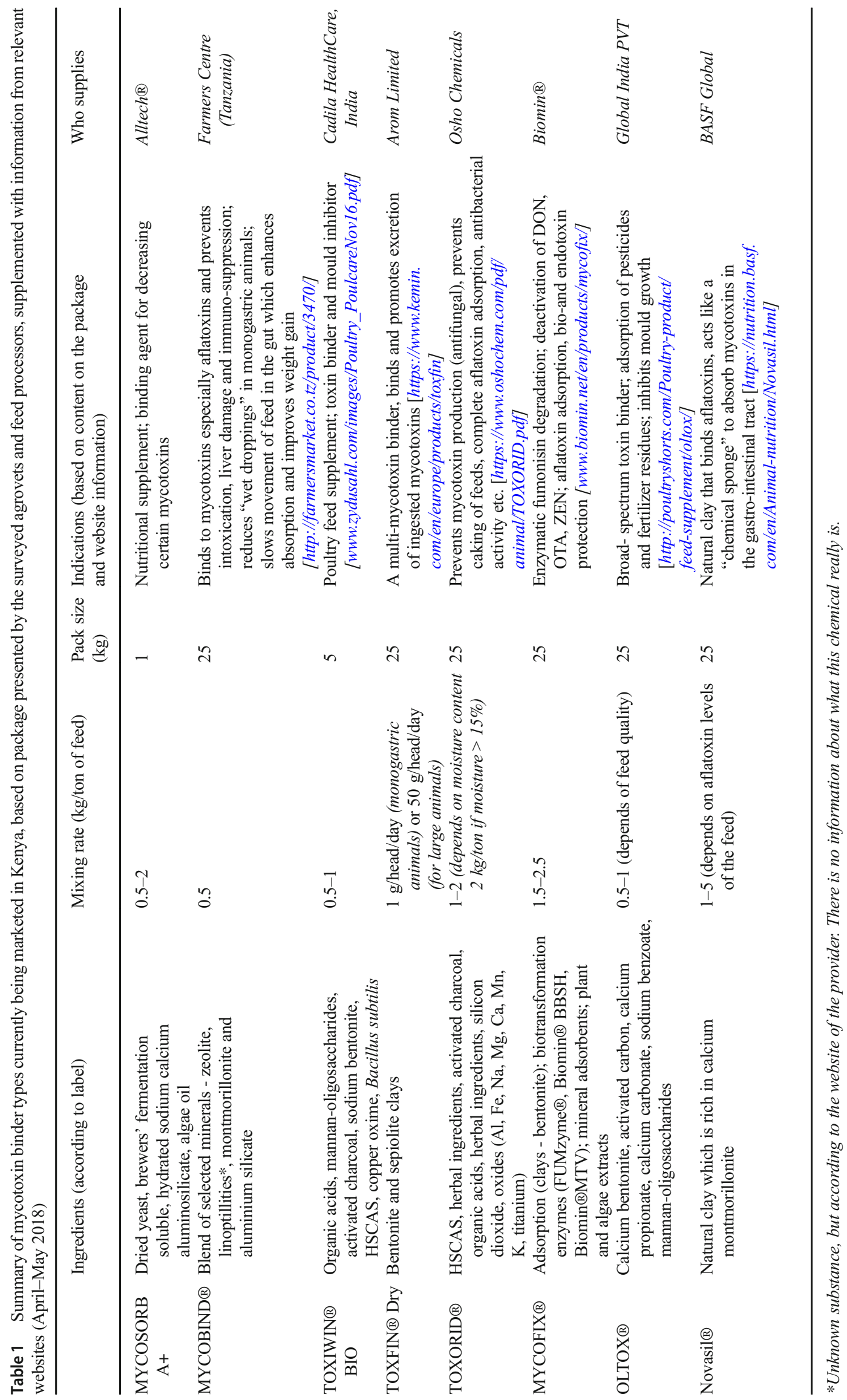


Table 2 Cost in Ksh of mycotoxin binders available in urban and peri-urban markets of Kisumu and Nairobi, April-May 2018, and as reported by the sellers

\begin{tabular}{|c|c|c|c|c|c|c|c|c|}
\hline & Mycosorb $\AA$ & Toxorid® & Toxiwin Bio® & Toxifin Dry® & $\mathrm{T} 5 \mathrm{X} \circledast$ & Mycobind $\AA$ & Mycofix® & Novasil@ \\
\hline Cost (Ksh) / kg & 1050 & 515 & 360 & 450 & 400 & 700 & 450 & $290^{*}$ \\
\hline No. of outlets where data were available & 2 & 1 & 1 & 1 & 1 & 2 & 1 & \\
\hline
\end{tabular}

${ }^{*}$ None of the visited outlets sold Novasil@ (or used it in feed processing), and therefore data from the Kenyan reseller was used to give cost of the product per $\mathrm{Kg}$

\subsection{Research gaps identified during the key informant interviews}

A number of research gaps were identified during the interviews (Table 4); when addressed, filling these gaps would support the development of standards for better regulation of mycotoxin binder use in the country.

\section{Discussion}

Over 50 animal feed sellers (including 11 millers) were identified in the present study. A previous study on the animal feed industry in Kenya estimated around 200 feed millers, concentrated in Nairobi and central Kenya: more than $90 \%$ were small-scale and around $40 \%$ of feed was for the dairy sector (KMT 2016). Most of the feed outlets in our study were agrovets. Agrovets are the main suppliers of agricultural and veterinary products in most of Kenya, especially maize producing areas and where livestock husbandry is intense. Although agrovets by law should be owned or managed by a veterinarian or para-veterinarian, vendors may not always be well informed about the products sold (Higham et al. 2016). The wide range of goods sold, as demonstrated by our study, also militates against specialist knowledge.

Our study found good awareness of supply chain problems that reduce feed quality. The high contamination of feed with aflatoxins in Kenya is well-documented has several factors including: widespread practice of using spoilt grains in the formulation of dairy rations (Lanyasunya et al. 2005); direct feeding of spoiled cereals to livestock (Kiama et al. 2016); climatic conditions that favour growth of aflatoxin producing moulds; weak surveillance tools; and the inability of farmers to meet minimum requirements for safer storage. The use of mycotoxin binders provides farmers with another option to block aflatoxin entry into the dairy value chain, avoiding the harmful health effects aflatoxin would cause once ingested (Whitlow 2006), as well as its risk of transfer to milk.

While all the millers were aware of mycotoxins binders only half of the agrovet dealers were aware of them and fewer than $10 \%$ sold them. Moreover, processors used binders in an ad hoc rather than hazard-based way. The study did find evidence for eight different types of binder being used in Kenya. Assuming an average of $2 \mathrm{~kg}$ binder per tonne of feed, the amount imported would correspond to 120 thousand tonnes of treated feed or around $16 \%$ of livestock feed produced in Kenya (KMT 2016).

Both clay-based and yeast-based mycotoxin binder types were reported in the study. Novasil@ is one of the most extensively studied clays (Ramos et al. 1996; Bulent et al. 2006; Phillips et al. 2008; Marroquin-Cardona et al. 2009; Kolosova and Stroka 2012). It is a phyllosilicate that contains HSCAS (Huwig et al. 2001; Phillips et al. 2008). Mycosorb®, marketed by Alltech (www.alltech.com/mycosorb-a-plus), is a yeast-based mycotoxin binder. Saccharomyces cerevisiae can bind aflatoxins transforming them to non-toxic substances
Table 3 Factors likely contributing to occurrence of aflatoxins in milk produced in urban and peri-urban areas, according to feed processors in Kenya in April-May 2018

\begin{tabular}{|c|c|}
\hline & What was considered a cause of aflatoxin contamination \\
\hline \multirow[t]{3}{*}{ Feed handling and storage } & $\begin{array}{l}\text { - Lack of awareness about mould growth and aflatoxins (farmers, } \\
\text { transporters, feed traders) }\end{array}$ \\
\hline & $\begin{array}{l}\text { Poor grain storage practices - at the farm level where cereals are stored } \\
\text { in damp paces, and for processed feeds (and raw materials) at the } \\
\text { retail shops }\end{array}$ \\
\hline & - Long storage of products which favours mould growth and spoilage \\
\hline \multirow{4}{*}{$\begin{array}{l}\text { Source and transportation of raw } \\
\text { materials, and processing }\end{array}$} & • Shipping spoilage \\
\hline & - Transportation of products during the rainy season \\
\hline & - Poor processing of the products in source country \\
\hline & $\begin{array}{l}\text { - Farmers cannot afford to purchase complete feeds make their own mix } \\
\text { with poor quality, often local, materials }\end{array}$ \\
\hline Government policies & -Weak regulation of policies governing transport of raw materials \\
\hline
\end{tabular}


(EFSA 2009; Carlos et al. 2013). Novasil is imported into Kenya, based on data from the Directorate of Veterinary offices. ILRI has recently implemented a pilot study to assess the use of this product in selected smallholder dairy systems of Kenya. However, none of the small millers interviewed included Novasil ${ }^{\circledR}$ in the production processes, and none of the agrovets sold it. It is therefore possible that the product is used by medium and large-scale feed processors, who were not included in the present study.

Key informants considered it important to have information on the efficacy of binders in order to regulate them appropriately. There is very limited information on the efficacy of binders in the context of Kenya. Numerous mycotoxin detoxifiers are commercially available in many countries. Although claims are made about their aflatoxin mitigation effects, many products are not registered as mycotoxin detoxifiers because it is typically easier to register under other categories such as technical additives, feedstuff or digestibility enhancers (De Mill et al. 2015). While the effect of these products on aflatoxin reduction has been demonstrated in many studies, there is considerable variation in their efficacy (Huwig et al. 2001; Phillips et al. 2002; Sahin and Sehu 2007). A website consulted as part of the current study made reference to a binder ingredient for which no other information could be found. Mycotoxin binders should be rigorously evaluated in both in vitro and in vivo studies (Phillips et al. 2008). In addition, for those binders that meet the inclusion criteria, Brazil recommends their re-testing every six months (in vitro) and every 2 years (in vivo) to ensure the manufacturers are selling the same product that was initially approved (Zaviezo 2009).

Kenya imports mycotoxin binders as feed additives and there are no specific standards governing their use in the country. The aflatoxin safety requirement is for the final product (feed) to have AFB1 levels that does not exceed the maximum limit (ML) of $5 \mu \mathrm{g} / \mathrm{Kg}$. Such a limit would ensure the amount of AFM1 that is released in milk does not exceed the WHO/ FAO ML of $0.05 \mu \mathrm{g} / \mathrm{Kg}$. However, these limits are frequently exceeded in dairy feeds, with studies finding levels higher than $9000 \mu \mathrm{g} / \mathrm{Kg}$ (Senerwa et al. 2016). While aflatoxin limits should be set as low as reasonably achievable to mitigate significant public health risks (CODEX 2009), low and middle-income countries such as Kenya also have to ensure that regulations are feasible, and any actions taken do not affect food security (Sirma et al. 2018). Although, in theory, compliance with the set limits is assessed during routine factory and surveillance visits, studies have found that feed quality assurance (both internal and external) is very weak in Kenya (KMT 2016). Moreover, the dairy value chain in Kenya is informal to a very large extent, with $80 \%$ of milk being sold outside the formal sector and much of the feed value chain also informal (Omore et al. 2004; Republic of Kenya 2013; KMT 2016). This further complicates inspection and regulation as a tool to improve quality. Unsurprisingly, aflatoxin contamination has been reported in both formal and informal dairy market chains (Lindahl et al. 2018).

Some feed processors source their raw materials from neighbouring countries of East Africa. Quality is often low, perhaps because of the failure to impose quality controls on exports, the long transit time and poor transit quality (and rain exposure). In addition, there is a perception that the quality of raw materials meant for animal feed production is not important. The limited number of testing facilities in most border areas makes it difficult to ascertain quality of imports from neighbouring countries. Sampling and testing of aflatoxins, small quantities of compounds that are not evenly distributed, is not easy (Grace et al. 2015). Furthermore, high laboratory charges may limit routine testing for surveillance. The East African Community (EAC) has adopted the following as maximum limits for aflatoxins: $0.5 \mu \mathrm{g} / \mathrm{kg}$ for AFM1 in milk; $5 \mu \mathrm{g} / \mathrm{kg}$ for AFB1; and $10 \mu \mathrm{g} / \mathrm{kg}$ for total aflatoxins. Compliance to EAC standards will lead to better health and will also bring about easier trade within and outside the region. Harmonization of standards should consider factors such as the characteristics of animals kept as well as the available feed types (Grace et al. 2015).

Table 4 Research gaps that would need to be addressed to facilitate development of guidelines for regulating the use of mycotoxin binders in Kenya, April / May 2018

Suggested research question(s)

Effectiveness / usefulness

Quality

Effects on the environment

Effects of other feed sources
- How effective are mycotoxin binders when used to mitigate aflatoxin risks in Kenya? - are they working given the high and fluctuating levels of contamination?

- If the binders are not effective, what changes should be made to make them work? - what would be the dose rates for different levels of concentration

- How effective are mycotoxin binders against other important mycotoxins?

- How can one differentiate a good binder from a bad one? - what tests can be applied to assess this, and how can the farmer know?

- What is the effect of the aflatoxin-binder complex in the environment?

- How much of the aflatoxin contamination of feed is contributed by feed sources other than concentrate feeding, such as hay or silage? 


\section{Conclusions}

This study suggests the following conclusions:

- Further research: Different types of mycotoxin binders are being sold in the Kenyan markets. Tests to determine the local efficiency of binders are needed. Authorities could then use the results of these tests to define the specific criteria these binders need to meet before being sold in the markets. Brazil uses a three phased approach to approve the use of mycotoxin binders (Zaviezo 2009). Failure to implement regulations for mycotoxin binders negates guarantee of their safety (Murugesan et al. 2015).

- The use of mycotoxin binders is not a stand-alone strategy: The use of mycotoxin binders alone cannot solve the problem of aflatoxin contamination, and cannot replace good production, handling, manufacturing practices, which are the primary mycotoxin control strategies. Standards could be raised if success on mycotoxin binder use is proven.

- Affordability: The required doses for mycotoxin binders are quite small (about $0.5 \mathrm{~kg}$ in a tonne of feed). Selling mycotoxin binders in small quantities ( $1 \mathrm{~kg}$ vs. $25 \mathrm{~kg}$ ) may encourage more farmers to purchase the product, and will also remove weighing and re-packing operations, and so cancel the possibility of adulteration.

- Promoting awareness: It is important for stakeholders in the dairy value chain to understand the risks of aflatoxins, and the effects these cause in both animals and humans.

Acknowledgements This research was funded by Food Africa Programme with funds from the Ministry for Foreign Affairs of Finland, grant number 29891501 (Food Africa) and nested into a nutrition project funded by the CGIAR Research Program on Agriculture for Nutrition and Health. We acknowledge all the support received by government officials in Kisumu and Nairobi counties, as well as that received from farmers, agrovet shop owners, and feed millers interviewed in the course of the study.

\section{Compliance with ethical standards}

Conflict of interest The authors declare that they have no conflict of interest.

Open Access This article is distributed under the terms of the Creative Commons Attribution 4.0 International License (http:// creativecommons.org/licenses/by/4.0/), which permits unrestricted use, distribution, and reproduction in any medium, provided you give appropriate credit to the original author(s) and the source, provide a link to the Creative Commons license, and indicate if changes were made.

\section{References}

Anyango, G., Mutua, F., Kagera, I., Andang'o, P., Grace, D., \& Lindahl, J. F. (2018). A survey of aflatoxin M1 contamination in raw milk produced in urban and peri-urban areas of Kisumu County, Kenya.
Infection Ecology \& Epidemiology, 8. https://doi.org/10.1080/ 20008686.2018.1547094.

Azziz-Baumgartner, E., Lindblade, K., Gieseker, K., Rogers, H. S., Kieszak, S., Njapau, H., Schleicher, R., McCoy, L. F., Misore, A., DeCock, K., Rubin, C., Slutsker, L., \& the Aflatoxin Investigative Group. (2005). Case-control study of an acute aflatoxicosis outbreak, Kenya, 2004. Environmental Health Perspectives, 113, 1779-1783.

Bulent, K., \& Dobson, A. (2009). Biological strategies to counteract the effects of mycotoxins. Journal of Food Protection, 72, 2006-2016.

Bulent, K., Dobson, A. D., \& Var, I. (2006). Strategies to prevent mycotoxin contamination of food and animal feed: A review. Critical Reviews in Food Science and Nutrition, 46, 593-619.

Carlos, A., Fernanda, B., Carlos, C., Alessandra, V., \& Kasa, R. (2013). Recent Trends in Microbiological Decontamination of Aflatoxins in Foodstuffs In: Aflatoxins - Recent Advances and Future Prospects. https://www.intechopen.com/books/aflatoxins-recent-advancesand-future-prospects/recent-trends-in-microbiologicaldecontamination-of-aflatoxins-in-foodstuffs. Accessed on 22 February 2019.

CODEX. (2009). General standard for contaminants and toxins in food and feed (CODEX STAN 193-1995). http://www.fao.org/ fileadmin/user_upload/livestockgov/documents/1_CXS_193e.pdf. Accessed on 22 February 2019.

De Mill, T., Devreese, M., De Baere, S. De, Van Ranst, E., Eeckhout, M., De Backer, P., \& Croubels, S. (2015). Characterization of 27 mycotoxin binders and the relation with In Vitro Zearalenone adsorption at a single concentration. Toxins, 7, 21-33.

Dohoo, I., Martin, W., \& Stryhn, H. (2003). Veterinary Epidemiologic Research, S. M. McPike (ed), (AVC Inc, University of Prince Edward Island: Prince Edward Island).

EFSA. (2009). Review of mycotoxin-detoxifying agents used as feed additives : Mode of action , Efficacy and feed / food safety. https:// efsa.onlinelibrary.wiley.com/doi/epdf/10.2903/sp.efsa.2009.EN-22. Accessed on 22 February 2019, 6.

Giovati, L., Magliani, W., Ciociola, T., Santinoli, C., Conti, S., \& Polonelli, L. (2015). AFM1 in milk: Physical, biological, and prophylactic methods to mitigate contamination. Toxins, 7, 4330-4349.

Grace, D., Lindahl, J. F., Atherstone, C., Kang'ethe, E. K., Nelson, F., Wesonga, T., \& Manyong, V. (2015). Aflatoxin Standards for Feed. Knowledge Platform 2015 Situational Analysis for East Africa Region. Building an Aflatoxin Safe East African Community Technical Policy Paper 7. https://aflasafe.com/wp-content/uploads/ pdf/TPP-4-Aflatoxin-Impact-on-Animal-Health.pdf. Accessed on 22 February 2019.

Higham, L. E., Ongeri, W., Asena, K., \& Thrusfield, M. V. (2016). Characterising and comparing drug-dispensing practices at animal health outlets in the Rift Valley, Kenya: An exploratory analysis (part II). Tropical Animal Health and Production, 48, 1633-1643.

Huwig, A., Freimund, S., Kapelli, O., \& Dutler, H. (2001). Mycotoxin detoxication of animal feed by different adsorbents mycotoxin detoxication of animal feed by different adsorbents. Toxicology Letters, 122, 179-188.

IARC. (2012). A review of human carcinogens: chemical agents and related occupations IARC monographs on the evaluation of carcinogenic risks to humans, Vol. 100F, 225-248. https://monographs. iarc.fr/wp-content/uploads/2018/06/mono100F.pdf. Accessed on 22 February 2019.

Kagera, I., Kahenya, P., Mutua, F., Anyango, G., Kyallo, F., Grace, D., \& Lindahl, J. (2019). Status of aflatoxin contamination in cow milk produced in smallholder dairy farms in urban and peri-urban areas of Nairobi County: A case study of Kasarani Sub-County. Kenya. Infection Ecology \& Epidemiology, 9. https://doi.org/10.1080/ 20008686.2018.1547095. 
Kang'ethe, E. K., \& Lang'a, K. (2009). Aflatoxin B1 and M1 contamination of animal feeds and milk from urban centers in Kenya. African Health Sciences, 9, 218-226.

Kang'ethe, E., Gatwiri, M., Sirma, A. J., Ouko, E. O., Mburugu-Musoti, C. K., Kitala, P. M., Nduhiu, G. J., Nderitu, J. G., Mungatu, J. K., Hietaniemi, V., Joutsjoki, V., \& Korhonen, H. J. (2017). Exposure of Kenyan population to aflatoxins in foods with special reference to Nandi and Makueni counties. Food Quality and Safety, 1, 131-137.

Kiama, T. N., Lindahl, J. F., Sirma, A. J., Senerwa, D., Waithanji, E. M., Ochungo, P. A., Poole, E. J., Kang'ethe, E. K., \& Grace, D. (2016). Kenya dairy farmer perception of moulds and mycotoxins and implications for exposure to aflatoxins: A gendered analysis. African Journal of Food, Agriculture, Nutrition and Development, 16, 11106-11125.

KMT. (2016). Mapping animal feed manufacturers and ingredient supplies in Kenya. http://www.kenyamarkets.org/wp-content/uploads/ 2017/10/Study-Report-on-Animal-Feed-Millers-and-IngredientSuppliers-in-Kenya-2017.pdf. Accessed on 22 February 2019.

Kolosova, A., \& Stroka, J. (2012). Evaluation of the effect of mycotoxin binders in animal feed on the analytical performance of standardised methods for the determination of mycotoxins in feed. Food Additives \& Contaminants, 29(12), 1959-1971.

Lanyasunya, T., Wamae, L., Musa, H., Olowofeso, O., \& Lokwaleput, I. (2005). The risk of mycotoxins contamination in dairy feed and milk on smallholder dairy farms. Pakistan Journal of Nutrition, 4, 162 169.

Lewis, L., Onsongo, M., Njapau, H., Schurz-Rogers, H., Luber, G., Kieszak, S., Nyamongo, J., Backer, L., Dahiye, A. M., Misore, A., DeCock, K., \& Rubin, C. (2005). Aflatoxin contamination of commercial maize products during an outbreak of acute aflatoxicosis in eastern and Central Kenya. Environmental Health Perspectives, 113, $1763-1767$.

Lindahl, J. F., Kagera, I. N., \& Grace, D. (2018). Aflatoxin M1 levels in different marketed milk products in Nairobi, Kenya. Mycotoxin Research, 34, 289-295. https://doi.org/10.1007/s12550-018-03234.

Mallmann, C., \& Dilkin, P. (2012). Brazilian mycotoxin experiences. International Pig Topics, 27, 28-30.

Marroquin-Cardona, A., Deng, Y., Taylor, J., Hallmark, C., Johnson, N., \& Phillips, T. (2009). Food Additives \& Contaminants : Part a In Vitro and in vivo characterization of mycotoxin- binding additives used for animal feeds in Mexico. Food Additives \& Contaminants: Part A, 26(5), 733-743.

McLean, M., \& Dutton, M. (1995). Cellular Interractions and metabolism of aflatoxin: An update. Pharmacology \& Therapeutics, 65, 163192

Murugesan, G., Ledoux, D., Naehrer, K., Berthiller, F., Applegate, T., Grenier, B., Phillips, T., \& Schatzmayr, G. (2015). Prevalence and effects of mycotoxins on poultry health and performance, and recent development in mycotoxin counteracting strategies. Poultry Science, 94, 1298-1315.

Mutegi, C., Ngugi, H., Hendriks, S., \& Jones, R. (2012). Factors associated with the incidence of Aspergillus section Flavi and aflatoxin contamination of peanuts in the Busia and Homa Bay District of Western Kenya. Plant Pathology, 51, 1143-1153.

Mwihia, J. T., Straetmans, M., Ibrahim, A., Njau, J., Muhenje, O., Guracha, A., Gikundi, S., Mutonga, D., Tetteh, C., Likimani, S., Breiman, R. F., Njenga, K., \& Lewis, L. (2008). Aflatoxin levels in locally grown maize from Makueni District, Kenya. East African Medical Journal, 85, 311-317.

Omore, A., Staal, S., \& Randolph, T. (2004). Overcoming barriers to informal milk trade in Kenya. Paper prepared for the EGDIWIDER (Expert Group on Development Issues/World Institute for Development Economics Research) conference on unlocking human potential linking the informal and formal sectors, Helsinki, Finland, 17-18 September 2004. https://cgspace.cgiar.org/handle/ 10568/1042. Accessed on 22 February 2019.

Phillips, T. D., Lemke, S. L., \& Grant, P. G. (2002). Characterization of clay-based enterosorbents for the prevention of aflatoxicosis. Advances in Experimental Medicine and Biology, 504, 157-171.

Phillips, T. D., Afriyie- Gyawu, E., Williams, J., Huebner, H., Ankrah, N., Ofori-Adjei, D., Jolly, P., Johnson, N., Taylor, J., Xu, L., \& Wang, J. (2008). Reducing human exposure to aflatoxin through the use of clay : A review. Food Additives and Contaminants, 25, 134-145.

Ramos, A., Fink-gremmels, J., \& Hernandez, E. (1996). Prevention of toxic effects of mycotoxins by means of nonnutritive adsorbent compounds. Journal of Food Protection, 59, 631-641.

Republic of Kenya. (2013). Republic of Kenya Ministry of Agriculture, livestock, and fisheries. State Department of livestock. Sessional paper no. 5 of 2013. Towards a competitive and sustainable dairy industry for economic growth in the 21 st century and beyond. http:// www.kenyamarkets.org/wp-content/uploads/2016/06/NationalDairy-Development-Policy-2013.pdf. Accessed on 22 February 2019.

Sahin, T., \& Sehu, A. (2007). Effects of hydrated sodium calcium Aluminosilicate (HSCAS ) on aflatoxicosis in broilers. Arch.Getfugelk, 71, 88-92.

Senerwa, D., Sirma, A., Mtimet, N., Kangethe, E., Grace, D., \& Lindahl, J. (2016). Prevalence of aflatoxin in feed and cow milk from five counties in Kenya. African Journal of Food Agriculture Nutrition and Development, 16, 11004-11021.

Sirma, A., Lindahl, J. F., Makita, K., Senerwa, D., Mtimet, N., Kang'ethe, E. K., \& Grace, D. (2018). The impacts of aflatoxin standards on health and nutrition in sub-Saharan Africa: The case of Kenya. Global Food Security, 18, 57-61.

Stata. (2017). Stata Statistical Software: Release 15. College Station, TX: StataCorp LLC.

Whitlow, W. (2006). Evaluation of Mycotoxin Binders. In: 4th MidAtlantic Nutrition Conference. University of Maryland, College Park, MD, 20742, 132, Zimmermann, N. G, Ed. https://www. researchgate.net/publication/238692281_Evaluation_of mycotoxin_binders. Accessed on 6 July 2018.

Wild, C., \& Turner, P. (2002). The toxicology of aflatoxins as a basis for public health decisions. Mutagenesis, 17, 471-481.

Yard, E. E., Daniel, J. H., Lewis, L. S., Rybak, M. E., Paliakov, E. M., Kim, A. A., Montgomery, J. M., Bunnell, R., Abudo, M. U., Akhwale, W., Breiman, R. F., \& Sharif, S. K. (2013). Human aflatoxin exposure in Kenya, 2007: A cross-sectional study. Food Additives and Contaminants - Part A Chemistry, Analysis, Control, Exposure and Risk Assessment, 30, 13221331.

Zaviezo, D. (2009). Brazilian experiences with mycotoxins. International Poultry Production, 17, 11-13. 


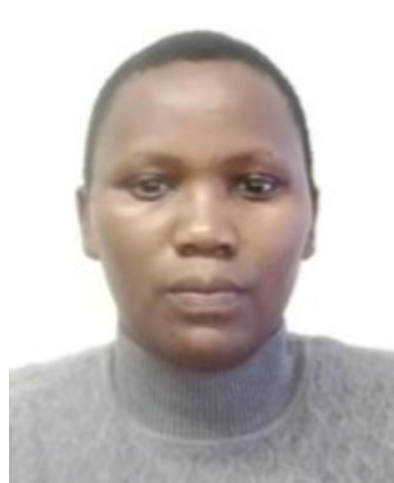

Florence Mutua is a Veterinary Epidemiologist and a consultant at the International Livestock Research Institute in Nairobi. Until September 2018, she taught at the Department of Public Health, Pharmacology and Toxicology, University of Nairobi. Her research interests are in food safety and animal health, with wide experience working in smallholder farming systems.

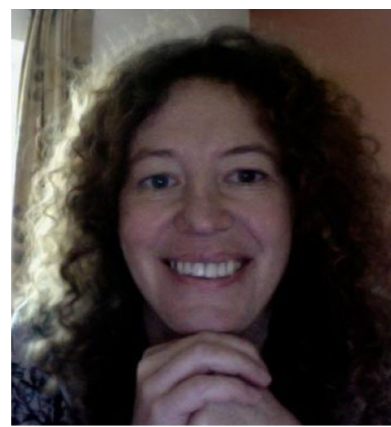

Delia Grace is an epidemiologist and leads the Health Program at ILRI and the Flagship on Food Safety in the CGIAR research program on agriculture and health. She has been a lead researcher in food safety in informal markets for several decades. She has led or contributed to evidence syntheses and investment advice for World Bank, DFID, USAID, ACIAR, BMGF, FAO, OIE, WHO, AU-IBAR, OECD and others.

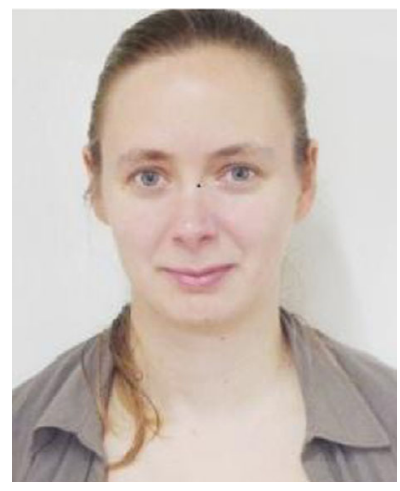

Johanna Lindahl is a joint appointee between ILRI, Swedish University of Agriculture and Uppsala University. She has a background in veterinary medicine and ten years' experience in academia and research. She leads aflatoxin work in ILRI's Health Program 